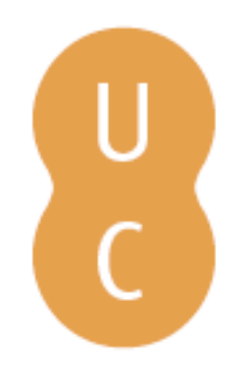

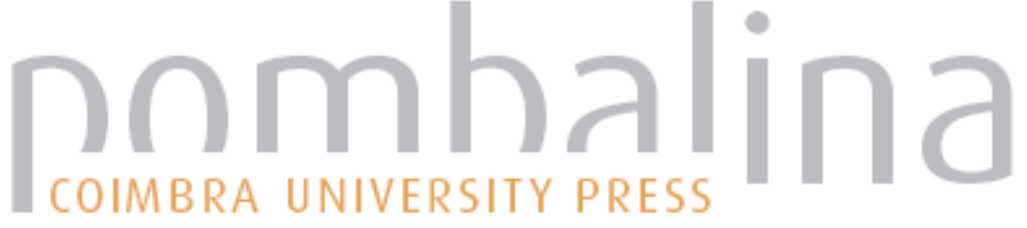

\section{A Universidade de Coimbra e o Brasil: uma relação de passado com futuro}

Autor(es): $\quad$ Paiva, José Pedro; Bernardes, José Augusto Cardoso

Publicado por: Imprensa da Universidade de Coimbra

URL

persistente:

URI:http://hdl.handle.net/10316.2/30708

DOI:

DOI:http://dx.doi.org/10.14195/978-989-26-0308-7_1

Accessed : $\quad$ 3-Nov-2017 22:47:38

A navegação consulta e descarregamento dos títulos inseridos nas Bibliotecas Digitais UC Digitalis, UC Pombalina e UC Impactum, pressupõem a aceitação plena e sem reservas dos Termos e Condições de Uso destas Bibliotecas Digitais, disponíveis em https://digitalis.uc.pt/pt-pt/termos.

Conforme exposto nos referidos Termos e Condições de Uso, o descarregamento de títulos de acesso restrito requer uma licença válida de autorização devendo o utilizador aceder ao(s) documento(s) a partir de um endereço de IP da instituição detentora da supramencionada licença.

Ao utilizador é apenas permitido o descarregamento para uso pessoal, pelo que o emprego do(s) título(s) descarregado(s) para outro fim, designadamente comercial, carece de autorização do respetivo autor ou editor da obra.

Na medida em que todas as obras da UC Digitalis se encontram protegidas pelo Código do Direito de Autor e Direitos Conexos e demais legislação aplicável, toda a cópia, parcial ou total, deste documento, nos casos em que é legalmente admitida, deverá conter ou fazer-se acompanhar por este aviso. 

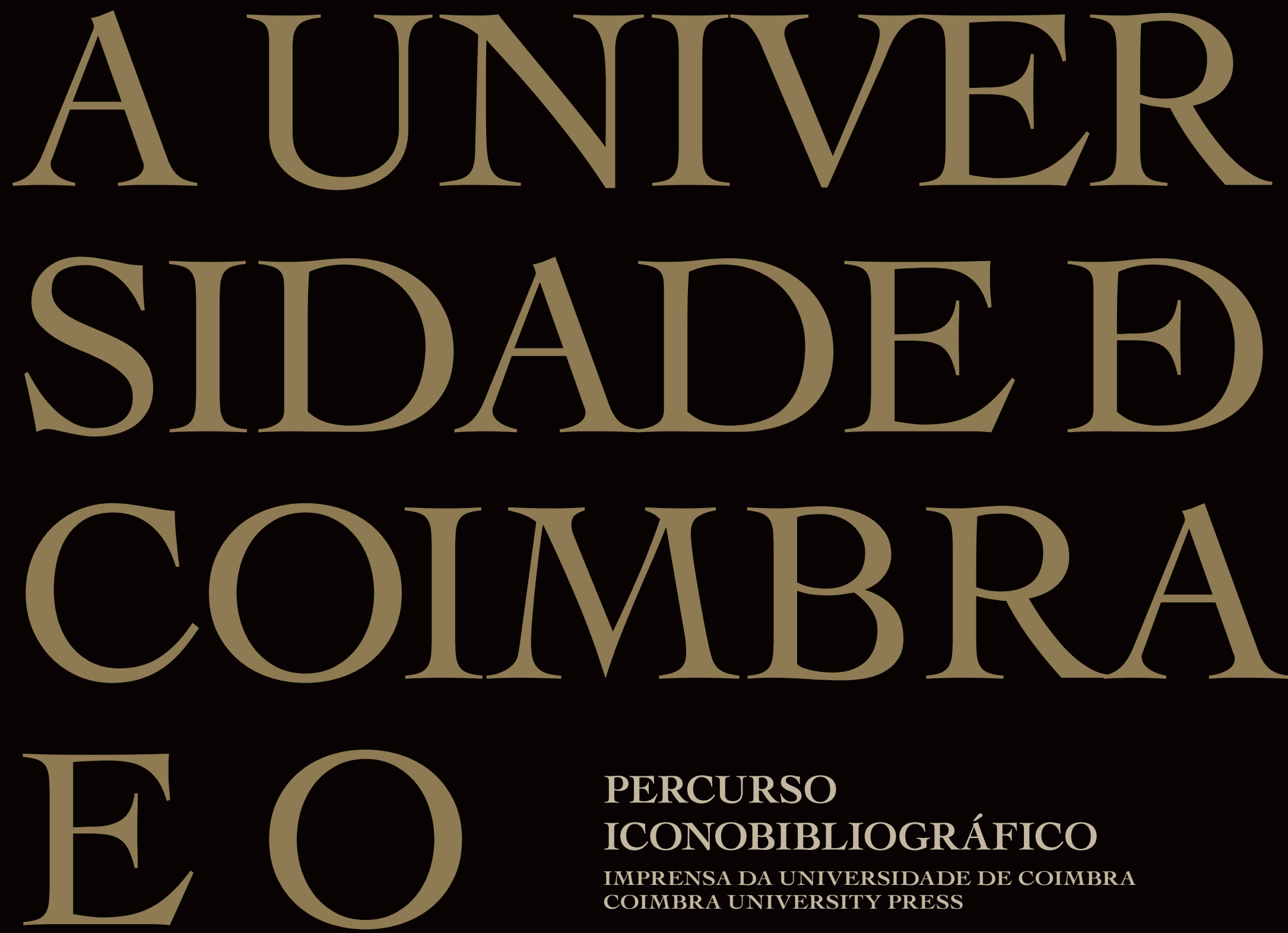

\section{PERCURSO}

\section{ICONOBIBLIOGRÁFICO}

IMPRENSA DA UNIVERSIDADE DE COIMBRA

COIMBRA UNIVERSITY PRESS

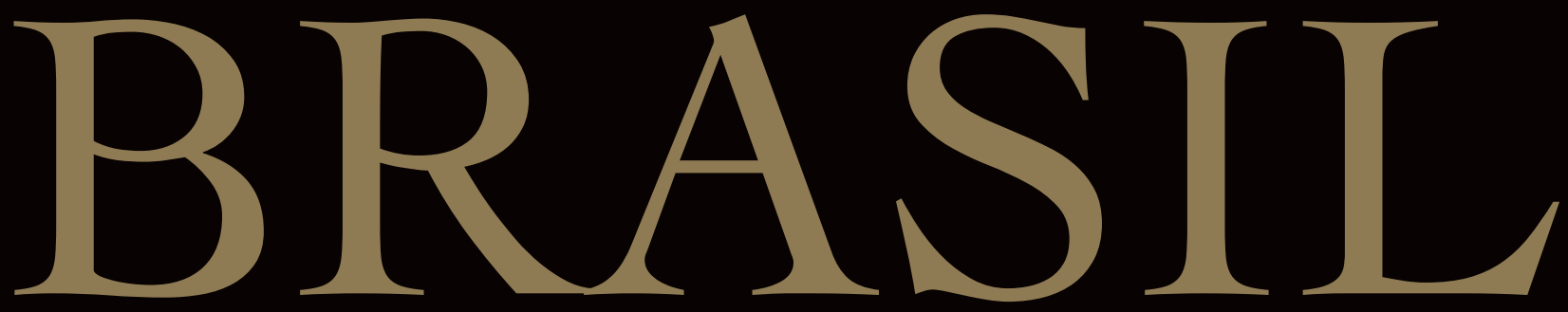


EDIÇÃO

Imprensa da Universidade de Coimbra

EMAIL: IMPRENSAUC@CI.UC.PT

URL: HTTP://WWW.UC.PT/IMPRENSA_UC

VENDAS ONLINE: HTTP://WWW.LIVRARIADAIMPRENSA.COM

Coordenação Científica

José Pedro Paiva

José Augusto Cardoso Bernardes

Textos

Joño Gabriel Silva

José Pedro Paiva

José Augusto Cardoso Bernardes

Joaquim Romero Magalhães

Décio Ruivo Martins

Fernando Ramos

Lúcio CunHa

Rui JaCINTO

JoÃo Arriscado Nunes

Maria Aparecida Ribeiro

Investigação e Conteúdos das Fichas Catalográficas

A.E. Maia do Amaral (Bguc)

Ana Maria Leitão Bandeira (auc)

Créditos Fotográficos

Miguel Pacheco/Redinteg Lda. (Digitalizações de livros e documentos)

Gilberto Pereira (exemplares zoológicos)

Pedro Casaleiro (exemplar etnográfico)

Tiago Maia/AuC (PeÇas museológicas - Ma)

Delfim Ferreira (arquitetura)

DESIGN

António Barros

INFOGRAFIA

Carlos Costa

EXECUÇÃo GRÁFICA

NORPRINT

ISBN

978-989-26-0161-8

Depósito Legal

Obra Publicada com o Patrocínio de 

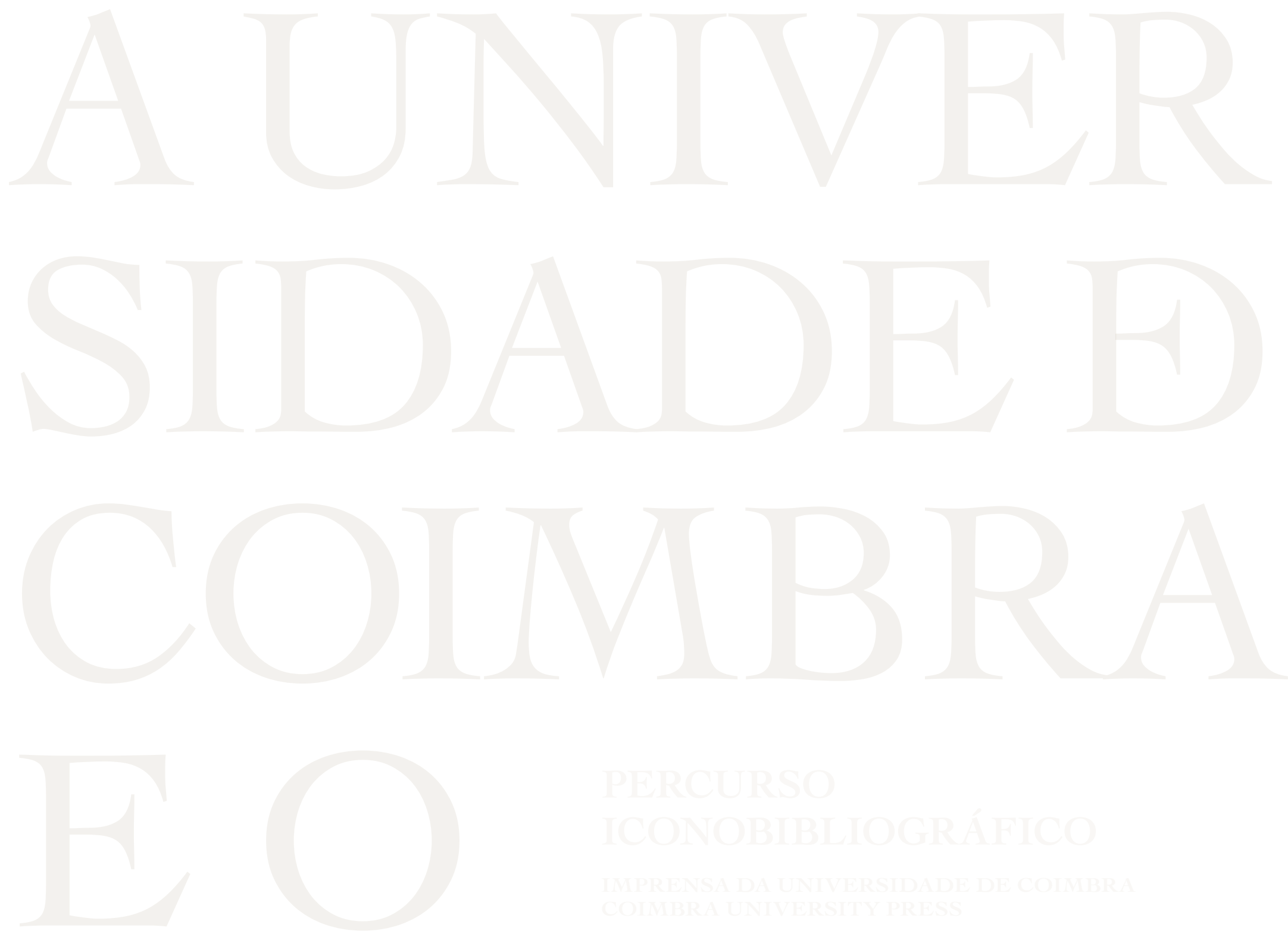

PRTOUROO
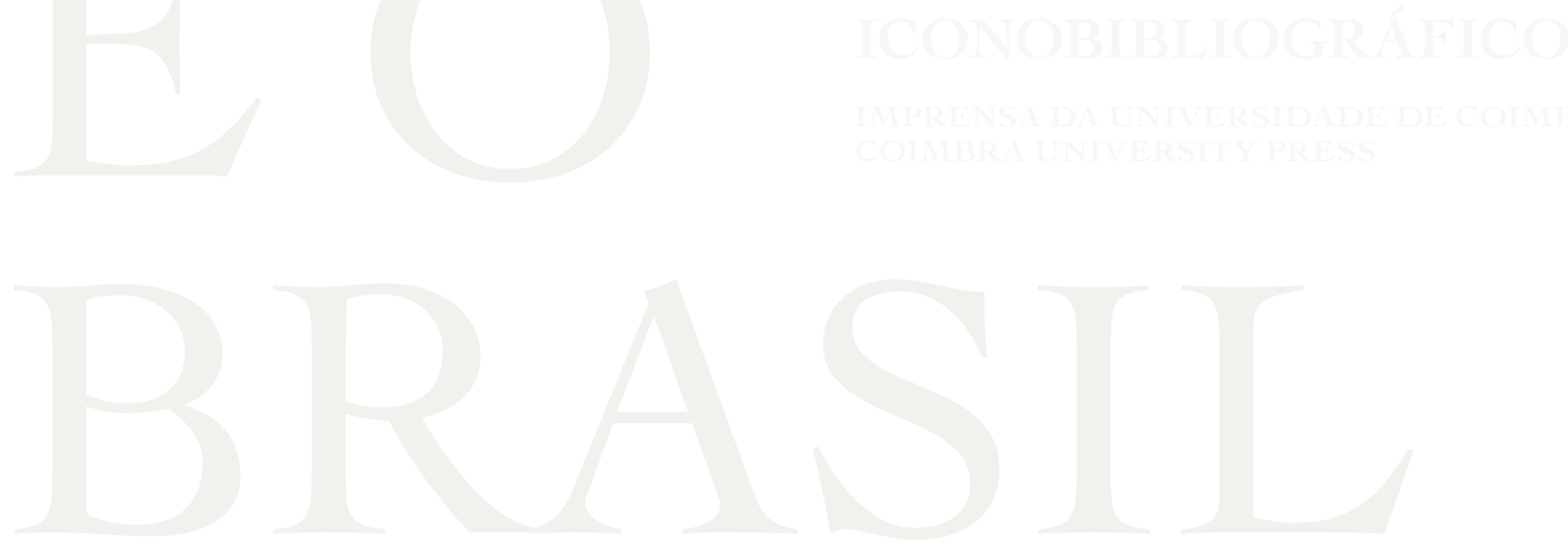
(Página deixada propositadamente em branco) 


\title{
A Universidade de Coimbra e o Brasil uma relação de Passado com Futuro
}

\author{
José Pedro Paiva \\ José Augusto Cardoso Bernardes
}





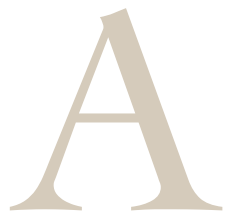

s relações entre o Brasil e Portugal não são simples de avaliar. Existem, por um lado, francos motivos de exaltação: o primeiro de todos resulta, sem dúvida, da duradoura partilha de uma Língua comum, ágil e clara nos requisitos de comunicação e ainda portadora de uma memória histórica, literária e cultural assumida pelos dois povos; existem, depois, perspetivas de cumplicidade económica e geopolítica que a globalização parece tornar ainda mais promissoras. Mas não pode ocultar-se que nessas relações subsistem dificuldades menos compreensíveis. A circulação dos bens culturais, por exemplo, está longe de ser perfeita. Assim sucede com o cinema ou com as artes figurativas; e tal como acontece sobretudo com o livro - o designado "livro técnico" - mas também o histórico, ensaístico e mesmo o ficcional. Contra o que seria legítimo esperar, apesar da confluência no idioma que a serve, a cultura continua a encontrar dificuldades para atravessar o Atlântico nos dois sentidos, com a regularidade que se impõe.

A ideia que se tem é que, mesmo sendo já profundas, as relações luso-brasileiras têm ainda uma enorme margem para crescer. Nessa margem, ampla e diversificada, inscrevem-se as parcerias no campo do Ensino e da Investigação. Existem progressos significativos, alguns deles consumados nos últimos anos; mas não há dúvida de que a cooperação entre as universidades dos dois países não é ainda o que poderia ser.

Para que essa cooperação se acentue e ganhe laços mais fortes e estruturados é, desde logo, necessário que se instale uma visão prospetiva, sendo igualmente imperativo que venha ao de cima uma memória comum. Ora, se a ideia de futuro tem que ser ajustada em cada presente, a memória não pode ser inventariada e compreendida com menos cuidado. Pelo contrário. Nas suas diversas vertentes, também ela carece de um método e de um sentido, para ser efetivamente colocada ao serviço da causa da aproximação entre o Brasil e Portugal.

As relações entre o Brasil e a Universidade de Coimbra vêm conhecendo, desde o último quartel do século XVI, momentos de diferente natureza mas quase sempre de muita intensidade: desde o século XVIII, quando o número de alunos provenientes da então colónia portuguesa chegou a rondar os $10 \%$ da comunidade estudantil coimbrã, 
até aos dias de hoje, marcados pela existência de numerosos programas de intercâmbio formativo, a Universidade de Coimbra teve mestres e reitores de origem brasileira, outorgou títulos honoríficos a individualidades do Brasil que se distinguiram no plano científico e no plano cívico, acolheu e participou em programas de investigação nos mais diferentes domínios, celebrou e estudou a língua comum e as culturas multiformes a que esse idioma deu origem.

Visando assinalar a importância dessas relações, o Arquivo e a Biblioteca da Universidade decidiram promover uma exposição documental e iconobibliográfica, congregando e disponibilizando algumas das muitas espécies que se guardam nos seus acervos, respeitando a domínios tão diversos como a História, as línguas indígenas brasileiras, a Literatura, a Geografia, a evangelização, a emigração, ou a vida político-militar.

É esse o sentido da presente iniciativa. No contexto de uma necessidade sentida por ambas as partes, justificava-se trazer à luz do dia sinais certificadores da intensa relação que sempre se verificou entre a Universidade de Coimbra e o Brasil. Nesse plano e respondendo a um dos vetores estratégicos da atuação da Reitoria da Universidade (assumido com especial ênfase pelo magnífico Reitor e pela Senhora Vice-Reitora para a Cultura) o Arquivo e a Biblioteca Geral decidiram participar na Semana Cultural de 2012, levando por diante uma mostra desses mesmos sinais. Só poderia ser uma exposição muito selecionada, tanta é a abundância de documentos (impressos, manuscritos e iconográficos) que ambas as instituições custodiam, dizendo diretamente respeito à presença de brasileiros na nossa Universidade Coimbra e também do impacto que tiveram membros da Academia conimbricense em múltiplos planos da vida do país irmão, desde o século XVI aos nossos dias.

Essa seleção difícil, bem como a complexa tarefa de compor o roteiro da exposição e os textos que a servem, ficou essencialmente ao cuidado de dois técnicos superiores de excecional craveira (um do Arquivo e outro da Biblioteca). A ambos (Drs Ana Maria Bandeira e António Eugénio Maia Amaral), conhecedores competentes do acervo das instituições que servem, se fica a dever o levantamento escrupuloso e a descrição pormenorizada de todas as peças.

Mas uma Exposição desta natureza requeria um Catálogo que a complementasse. Só assim os seus ecos podem perdurar para além do tempo em que estiver patente ao olhos do público no piso intermédio da Biblioteca Joanina (ela própria tão fielmente evocativa de uma história comum aos dois povos). E não poderia ser um Catálogo que se limitasse a replicar fotograficamente os objetos dispostos na sintaxe própria do livro. Entendeu-se assim que se deveria levar um pouco 
mais longe o esforço, solicitando a professores e investigadores de diferentes áreas do saber que, refletindo sobre o seu conhecimento e o seu protagonismo em parcerias luso-brasileiras no âmbito dos plurais saberes científicos ministrados na Universidade, concebessem textos que de alguma forma afiançassem a força desta relação tão peculiar. É com muito gosto que verificamos que, apesar do escasso tempo de que cada um dispôs, esse pedido pôde ser aceite por boa parte dos que foram contactados. Nesse sentido, os ensaios que abrem o volume (alguns numa orientação mais retrospetiva outros optando por um registo de diagnóstico; uns situando-se em âmbitos mais gerais outros colocando-se num plano mais alargado) constituem, ao mesmo tempo, testemunhos vivos de uma relação muito particular e garantia de duas facetas: de que a Universidade de Coimbra vai continuar a ser uma instituição de importância inigualável em terras brasileiras e de que a memória do Brasil na Alma Mater Conimbrigensís, sendo já excecionalmente rica, há-de continuar em construção nos anos vindouros.

Coimbra, 1 de março de 2012 • Dia da Universidade de Coimbra

O Diretor do Arquivo

José Pedro Paiva

O Diretor da Biblioteca Geral

José Augusto Cardoso Bernarded 


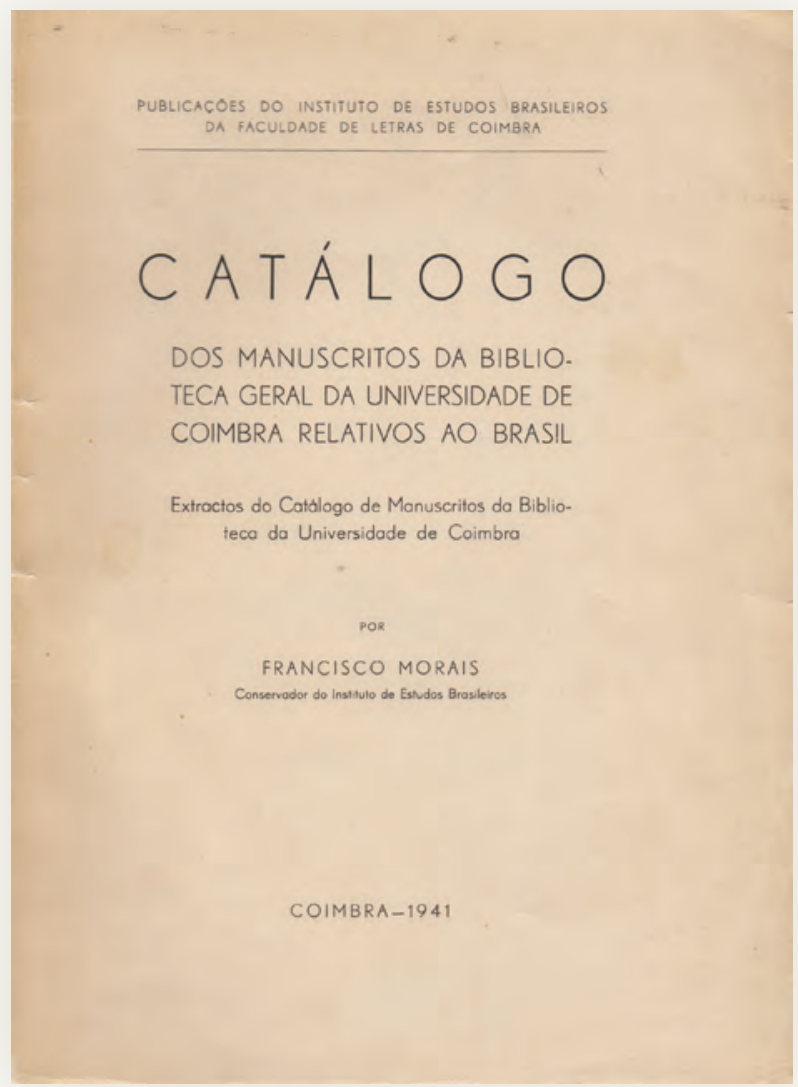

Capa do Catálogo dos manuscritos da Biblioteca Geral relativos ao Brasil por Francisco Morais, que é uma compilação de excertos dos catálogos publicados pela Biblioteca Geral. Coimbra: Instituto de Estudos Brasileiros da Faculdade de Letras de Coimbra, 1941. 
(Página deixada propositadamente em branco) 
